\title{
On the Liquid/Solid Phase Equilibria in the Al-Rich Corner of the Al-Si-Ti Ternary System
}

\author{
O. Dezellus, B. Gardiola, J. Andrieux, M. Lomello-Tafin, and J.C. Viala
}

(Submitted December 20, 2013; published online February 5, 2014)

\begin{abstract}
The nature of liquid-solid phase equilibria in the Al-rich corner of the Al-Si-Ti system are determined by drawing three isothermal sections at 620,680 and $727^{\circ} \mathrm{C}$. The solubility of $\mathrm{Ti}$ in $\mathrm{Al}-\mathrm{Si}$ liquids is determined for four different compositions $(0,9,13$ and 18 at.\%Si) at temperature below $800{ }^{\circ} \mathrm{C}$. Combination of the two sets of experimental results leads to an attempt of liquidus projection. The primary crystallization surface of $\mathrm{Al}_{3} \mathrm{Ti}$ is found to extend up to 9.5 at. $\% \mathrm{Si}$ in the liquid phase at $620{ }^{\circ} \mathrm{C}$ and 11 at.\%Si at $727^{\circ} \mathrm{C}$. The solubility of $\mathrm{Ti}$ is found to be not significantly dependent on the Si content of the liquid. From DSC measurements and deduction on microstructure, the last invariant reaction of the solidification path is found to be quasi-peritectic: $\mathbf{L}+\tau_{1}-\mathbf{T i}_{7} \mathbf{A l}_{5} \mathbf{S i}_{12} \Leftrightarrow \mathbf{A l}+\mathbf{S i}$.
\end{abstract}

Keywords aluminum alloys, differential scanning calorimetry (DSC), invariant point, isopleth, isotherm, liquidus surface, ternary system

\section{Introduction}

The ternary Al-Si-Ti system presents different industrial interests on its wide composition range, from high temperature application in the Ti-rich corner to classical casting technologies in the Al-rich one. Indeed, during solidification of Al-Si casting alloys, the control over the nucleation step by inoculation of the liquid is a widely used technique to promote the formation of a fine and uniform equiaxed grain structure. The most widely used inoculants for Al-Si hypoeutectic alloys are based on master alloys containing Ti. However, even if an extensive literature exists on the subject, the influence of the Si content on the refining effect and the role of Ti remain not clear. ${ }^{[1-8]}$ Whatever the exact mechanism involved in grain refinement of Al-Si casting alloys by Ti containing master alloys, it is obvious that a better knowledge of the thermodynamics of the Al-Si-Ti system is required to elucidate this mechanism.

Despite the fact that many authors have contributed to the knowledge of the Al-Si-Ti system in the past (see the extensive review of Perrot ${ }^{[9]}$ ), the nature of phase equilibria in the Al-rich corner remains a still open question. According to the notation of solid phases suggested in the review by Perrot, ${ }^{[9]}$ the solid phases in equilibrium with Al-

O. Dezellus, B. Gardiola, J. Andrieux, and J.C. Viala, Laboratoire des Multimatériaux et Interfaces, Université Claude Bernard - UMR CNRS 5615, 43 Bd du 11 novembre 1918, 69100 Villeurbanne, France; and M. Lomello-Tafin, Laboratoire SYMME, Polytech' Annecy-Chambéry, Université de Savoie, 5 Chemin de Bellevue, 74940 Annecy-le-vieux, France. Contact e-mail: olivier.dezellus@ univ-lyon1.fr.

$\mathrm{Si}$ liquids with increasing $\mathrm{Si}$ content, for temperatures lower than $900{ }^{\circ} \mathrm{C}$, are respectively $\left(\mathrm{Al}_{x} \mathrm{Si}_{1-x}\right)_{3} \mathrm{Ti}$ (with a Si content up to 15 at.\%), the ternary compound $\tau_{2}-\mathrm{Ti}\left(\mathrm{Si}_{1-x} \mathrm{Al}_{x}\right)_{2}$ (with $0.15<x<0.3-\mathrm{C} 49, \mathrm{ZrSi}_{2}$ type), the ternary compound $\tau_{1}-\mathrm{Ti}_{7} \mathrm{Al}_{5} \mathrm{Si}_{12}$ (isostructural with $\mathrm{Zr}_{3} \mathrm{Al}_{4} \mathrm{Si}_{5}$ ) and pure silicon. Different authors have experimentally studied the nature of primary crystallization phases for $\mathrm{Al}-\mathrm{Si}$ melts and the agreement between their results is rather good. ${ }^{[10-12]}$ The relative stability of the two ternary compounds $\tau_{1}-\mathrm{Ti}_{7} \mathrm{Al}_{5} \mathrm{Si}_{12}$ and $\tau_{2}-\mathrm{Ti}\left(\mathrm{Si}_{1-x} \mathrm{Al}_{x}\right)_{2}$ is still unclear. According to Shob et al. ${ }^{[13]} \tau_{2}-\mathrm{Ti}\left(\mathrm{Si}_{1-x} \mathrm{Al}_{x}\right)_{2}$ is the only phase existing at $1200{ }^{\circ} \mathrm{C}$. Gupta et al. ${ }^{[14]}$ also reported that $\tau_{2}-\operatorname{Ti}\left(\mathrm{Si}_{1-x} \mathrm{Al}_{x}\right)_{2}$ does not appear in the isothermal section at $1000{ }^{\circ} \mathrm{C}$, however their results are suffering from an ambiguous identification of the two ternary compounds.

Finally, Liu et al. ${ }^{[12]}$ reported the difficulty to determine the respective decomposition temperature of the two compounds by thermal analysis because of kinetics effects.

Invariant reactions involving the liquid in the Al-rich corner of the ternary system have been studied by differential thermal analysis in the $10-14$ at. $\% \mathrm{Si}$ and $0-0.6$ at. $\% \mathrm{Ti}$ ranges. ${ }^{[10]}$ More recently, Liu et al. ${ }^{[12]}$ performed differential thermal analysis in a wider range of composition and proposed a reaction scheme that is based on deductions from the succession of thermal events observed on some ternary samples. The systematic study of Bulanova et al. ${ }^{[15]}$ was not dealing with the Al-rich corner of the system and even if the authors proposed an extension of reaction scheme in this low temperature range, their results will not be considered here. Zakharov et al. ${ }^{[10]}$ performed phase separation in the liquid state by centrifugation in order to analyze the composition of the liquid melt and especially its Ti content. The values of solubility reported for Ti in nearly eutectic AlSi melts are below 0.35 at. $\%$ at $820^{\circ} \mathrm{C}$.

The first thermodynamic assessment of the Al-Si-Ti ternary system is attributed to Youdelis. ${ }^{[16]}$ However, the calculations of Youdelis have been performed under the oversimplified hypothesis that $\mathrm{Si}$ was not soluble in solid $\mathrm{Al}_{3} \mathrm{Ti}$ and that existence of the ternary compounds $\tau_{1}$ and $\tau_{2}$ 
could be neglected. More recently, Gröbner et al. ${ }^{[1]}$ proposed an upgraded thermodynamic assessment of the Al-Si-Ti ternary system, taking into account the existence of ternary compounds and of the $\mathrm{Si}$ substitution in $\mathrm{Al}_{3} \mathrm{Ti}$. From their optimized parameters, the authors draw different conclusions. They firstly argued that $\mathrm{Al}_{3} \mathrm{Ti}$ is no longer in equilibrium with $\mathrm{Al}-\mathrm{Si}$ liquids beyond 1.3 at.\% $\% \mathrm{Si}$ and therefore that this phase cannot act as nucleant in $\mathrm{Al}-\mathrm{Si}$ casting alloys, in disagreement with previously reported studies. ${ }^{[16]}$ It is interesting to note that Gröbner et al. have chosen to develop their assessment on the experimental data of Zakharov et al. and the isothermal section determined at $700{ }^{\circ} \mathrm{C}$ by Raman and Schubert ${ }^{[18]}$ by discarding other sets of experimental results such as those of Liu et al. ${ }^{[12]}$ and Peronnet et al. ${ }^{[11]}$ for the most recent ones.

The aim of the present study is to bring new experimental results on solid/liquid phase equilibria in the Al-rich corner of the ternary system in order to clarify controversy and remove ambiguities. Three isopletic sections between Al-Si liquids and solid titanium have been drawn and more precisely, the composition of the liquidus has been determined. Moreover, the liquid/solid phase equilibria have been assessed for $\mathrm{Si}$ contents lower than 20 at.\% in three isothermal sections between 620 and $727^{\circ} \mathrm{C}$.

\section{Experimental Procedure}

\subsection{Liquidus Determination by Liquid Sampling}

Binary Al-Si alloys with known silicon contents were first prepared from pure aluminium (Alfa-Aesar 99.999\% $\mathrm{Al}$ ) and from pure silicon lumps (Alfa-Aesar 99.9995\% Si). For each experiment, a mass of about $80 \mathrm{~g}$ of these constituents was melted by radio frequency (rf) heating in an alumina crucible lined with $\mathrm{Al}_{2} \mathrm{O}_{3}$ powder. Temperature was measured with a precision better than $\pm 0.2{ }^{\circ} \mathrm{C}$ by plunging in the melt a K-type thermocouple protected with an alumina sheath. Known quantities of titanium were dissolved step-by-step in the melt by immersing in it small rods of pure titanium $(99.999 \%$ Ti from Goodfellow). Dissolution of $\mathrm{Ti}$ and saturation of the melt in $\mathrm{Ti}$ was ensured by a dwell time of about $2 \mathrm{~h}$ at $900{ }^{\circ} \mathrm{C}$ and a regular stirring. Next, the alloy was removed from the induction coil, disposed in a radiant furnace at $800{ }^{\circ} \mathrm{C}$ and leaved undisturbed for at least $4 \mathrm{~h}$ at constant temperature. During this time, the undissolved crystals of the solid phase settled to the bottom of the crucible because of their density $\left(\mathrm{Al}_{3} \mathrm{Ti}\right.$ : $3.38 \mathrm{~g} / \mathrm{cm}^{3}{ }^{[18]} \tau_{2}-\mathrm{Ti}\left(\mathrm{Si}_{1-x} \mathrm{Al}_{x}\right)_{2}: 3.70 \mathrm{~g} / \mathrm{cm}^{3}, \tau_{1}-\mathrm{Ti}_{7} \mathrm{Al}_{5} \mathrm{Si}_{12}$ : $\left.3.87 \mathrm{~g} / \mathrm{cm}^{3[18]}\right)$, which is higher than that of the Al-Si melt (between 2.3 and $2.4 \mathrm{~g} / \mathrm{cm}^{3[19]}$ ). After careful removal of the dross at the centre of the liquid surface, samples of liquid were taken from alloy melts by sucking through a silica tube (inner and outer diameters: 4 and $6 \mathrm{~mm}$, respectively). To avoid metal/oxide reaction, the inner surface of the tube has been coated with a layer of carbon black. Solidification of the melt in the carbon-lined silica tube upon sucking was almost instantaneous, and fine-grained homogeneous rods $10-30 \mathrm{~mm}$ in length were obtained. Temperature was continuously monitored during the liquid sampling and a decrease was observed from a few Kelvin (3-7 K) during immersion of the silica tube. As a consequence, the effective temperature of the sample was considered to be the mean value during liquid sampling with an accuracy of $\pm 3{ }^{\circ} \mathrm{C}$. Next, the temperature of the liquid was decreased (or increased) from a few tens of degrees, and the liquid leaved undisturbed during a minimum of $8 \mathrm{~h}$ before the next liquid sampling.

Small slices of $20-40 \mathrm{mg}$ were then cut from the ingots obtained after liquid sampling by a diamond wire saw and their Ti amount determined by two different techniques. First, some slices were embedded in resin to prepare polished sections that were examined by optical microscopy (OM), scanning electron microscopy (SEM) and characterized by electron probe microanalysis (EPMA) in wavelength dispersive $\mathrm{x}$-ray spectroscopy (WDS) mode. The latter analysis was carried out using a Camebax apparatus (Cameca) equipped with a wavelength dispersive spectrometer and an energy dispersive spectrometer (EDS). An accelerating voltage of $15 \mathrm{kV}$, a regulated beam current of $11 \mathrm{nA}$ and a counting time of $20 \mathrm{~s}$ were selected as standard operating parameters to analyze $\mathrm{Al}$ and $\mathrm{Si}$ by EDS. It was firstly verified by EDS analysis that the microstructure of the solidified alloy was fine enough to obtain areas of $100 \times 100 \mu \mathrm{m}^{2}$ representative of the nominal alloy with the right $\mathrm{Al} / \mathrm{Si}$ ratio. Next, WDS analysis of Ti was performed on the same representative areas by repeating six counts of $10 \mathrm{~s}$ in 10-12 different areas. All the counting rates obtained were subtracted for background and referred to counting rates recorded under the same conditions on pure element standards. Finally, for each sample, the value of Ti solubility was the mean of more than 60 analyses with an interval of confidence at $99.7 \%(U=2 u=3 \sigma / \sqrt{ } N$, with $N=60)$ that is typically about 0.002 at. $\%$.

Chemical analyses were also performed at Analytical Sciences Institute, National Center for Scientific Research (ISA CNRS), by plasma emission spectroscopy (ICP-AES) after chemical dissolution in commercially pure hydrochloric acid. For chemical analysis, the results are obtained with a relative uncertainty of about $5 \%$.

\subsection{Isothermal Sections}

The determination of liquid/solid phase equilibria and more precisely the determination of the nature of the solid phase in equilibrium with different Al-Si liquids saturated in Ti has been studied by the experimental techniques detailed in Ref 11. Powder compact pellets were performed by mixing of $\mathrm{Al}, \mathrm{Si}$ and Ti powders and cold compaction under $55 \mathrm{MPa}$. The chosen $\mathrm{Ti}$ content (about 0.4 at.\%) was optimized to ensure saturation of the liquid while being as low as possible. In such conditions, the nominal composition in Si was only slightly modified by the equilibrium with the solid phase during isothermal treatment and the composition of the liquid can be considered as being the same as the nominal Si content. Next, the pellets were heat treated at a constant temperature according to the typical following procedure: (i) $48 \mathrm{~h}$ at $680{ }^{\circ} \mathrm{C}$, slow cooling toward $620{ }^{\circ} \mathrm{C}$, dwell of 7 days at $620{ }^{\circ} \mathrm{C}$ under Ar, rapid cooling. (ii) $24 \mathrm{~h}$ at $620^{\circ} \mathrm{C}$ under air, water quenching. The 


\section{Author's personal copy}

aim of the first dwell of 7 days in procedure was to ensure that dissolution of Ti particulates and saturation of the liquid were effective, leading to the precipitation of the equilibrium solid phase. The second shorter dwell of $24 \mathrm{~h}$ was followed by water quenching in order to avoid that the liquid composition evolves during cooling, leading to the occurrence of unwanted monovariant or invariant reactions. Due to the low Ti content of the alloys, the amount of crystals was too low to be characterized by $\mathrm{x}$-ray diffraction (XRD) technique. Moreover, some isothermal treatments have also been performed on slices of the ingots used for the liquid sampling experiments. Slices were taken from the bottom part, where the settled crystals were present, allowing the study of liquid/solid phase equilibria. In both cases, after mounting the sample in resin and classical polishing procedure, the composition of the crystals was characterized by SEM/EDS in a Quanta FEI 250 FEG apparatus equipped with a SDD detector. Quantitative information was obtained by comparing the intensities of $\mathrm{x}$-ray characteristic of each element present in the specimen with the intensity of the same radiation emitted by a pure element standard. The concentration of each element in the specimen is calculated from the ratios between intensity in the specimen and in the standard using the PAP model. ${ }^{[20]}$ Pure Al, Si and Ti elements were used as physical standards and the IDFIX system of SAMX microanalysis was used to perform PAP corrections.

\subsection{DSC Measurements}

The temperature of the invariant reactions has been checked by differential scanning calorimetry (DSC) using a SETSYS Evolution device from Setaram. Several experiments were done on samples, which were prepared by arc melting under argon from pieces of pure aluminium, pure silicon and pure titanium with at least $99.999 \%$ purity, and others obtained from liquid sampling. Concerning the arcmelted samples, the residual oxygen was removed from the furnace by melting pure zirconium prior to alloy synthesis. In agreement with the values of the vapour pressure of elements, which are very low $\left(5.6 \times 10^{-6}, 1.6 \times 10^{-5}\right.$ and $2.2 \times 10^{-5} \mathrm{~atm}$ at $1900 \mathrm{~K}$ for Ti, Si and $\mathrm{Al}$, respectively ${ }^{[21]}$ ), no significant weight losses were observed, that ensures the value of the composition of the samples calculated by weighting. DSC measurements were performed in flowing argon, which was purified by passing through an $\mathrm{O}_{2}$ and $\mathrm{H}_{2} \mathrm{O}$ getter (Subtronic, model $500 \mathrm{~N}$ ) reaching to impurity content being lower than 0.1 and $0.4 \mathrm{ppm}$, respectively. Alumina crucibles were used and no interfacial reaction was found. The temperature has been calibrated by heating pure standard metals (Al, Ag and $\mathrm{Au})$ in alumina crucible using various heating rates $(0.1,1,2$ and $5{ }^{\circ} \mathrm{C} / \mathrm{min}$ ). The difference between the onset melting temperature of the standard $T_{\mathrm{m}}$ and its reference melting temperature $T_{\text {ref }}$ was expressed as a function of the heating rate $(r)$ and of the temperature of the calorimetric cell $(T)$ : $\Delta T=\mathrm{B}_{0}+\mathrm{B}_{1} T+\mathrm{B}_{2} r$.

The determination of the onset temperature of invariant plateau and the calculation of the coefficients have been monitored by the Calisto SETARAM Software. The temperature has been calculated by averaging the values of four measurements for the eutectic plateau of the Al-Si system and of nine measurements for the ternary system. The relative deviations, obtained from the expanded uncertainty $(U=2 u=2 \sigma / \sqrt{ } N$, with $N=4$ or $N=9)$ provide a coverage interval at the $95 \%$ level of confidence.

\section{Results}

\subsection{Determination of the Liquid/Solid Equilibria}

Two temperatures $\left(620\right.$ and $\left.680{ }^{\circ} \mathrm{C}\right)$ and several compositions (from Al-5 at. $\% \mathrm{Si}$ to $\mathrm{Al}-12$ at. $\% \mathrm{Si}$ ) have been investigated. After isothermal treatment and water quenching, some crystals were observed in the solidified liquid phase (see Fig. 1) and their compositions were determined by EDS analysis. The results of the present study are presented in Table 1 with results previously obtained in our lab at $727^{\circ} \mathrm{C}$. ${ }^{[11]}$

From Table 1, it appears that the highest $\mathrm{Si}$ content of liquids in equilibrium with $\mathrm{Al}_{3} \mathrm{Ti}$ varies from 9 at.\% $\mathrm{Si}$ at $620{ }^{\circ} \mathrm{C}$ to 11 at. $\% \mathrm{Si}$ at $727{ }^{\circ} \mathrm{C}$. This result is in agreement with most of the previous experimental studies, ${ }^{[12]}$ but disagrees with the optimization of Gröbner et al. ${ }^{[17]}$

It has to be noted that in agreement with previous results, ${ }^{[18]} \mathrm{EDS}$ analysis indicate that $\mathrm{Si}$ substitutes $\mathrm{Al}$ in the $\mathrm{Al}_{3}$ Ti phase up to 14 at. $\%$ at $727^{\circ} \mathrm{C}$. For liquids with a Si content higher than 10 at.\% the solid phase in equilibrium is found to be one of the two ternary compounds $\tau_{1}-\mathrm{Ti}_{7} \mathrm{Al}_{5} \mathrm{Si}_{12}$ or $\tau_{2}-\operatorname{Ti}\left(\mathrm{Si}_{x} \mathrm{Al}_{1-x}\right)_{2}$. Both compounds have a similar crystal structure: $\tau_{1}$ is isostructural with $\mathrm{Zr}_{3} \mathrm{Al}_{4} \mathrm{Si}_{5}$ with the space group I4/amd $d^{[18,22]}$ while the space group of $\tau_{2}$ is $\mathrm{CmCm}$ with a $\mathrm{ZrSi}_{2}$ prototype and a strukturbericht that is $\mathrm{C} 49 .{ }^{[18]}$ As a consequence they can hardly be distinguished by XRD

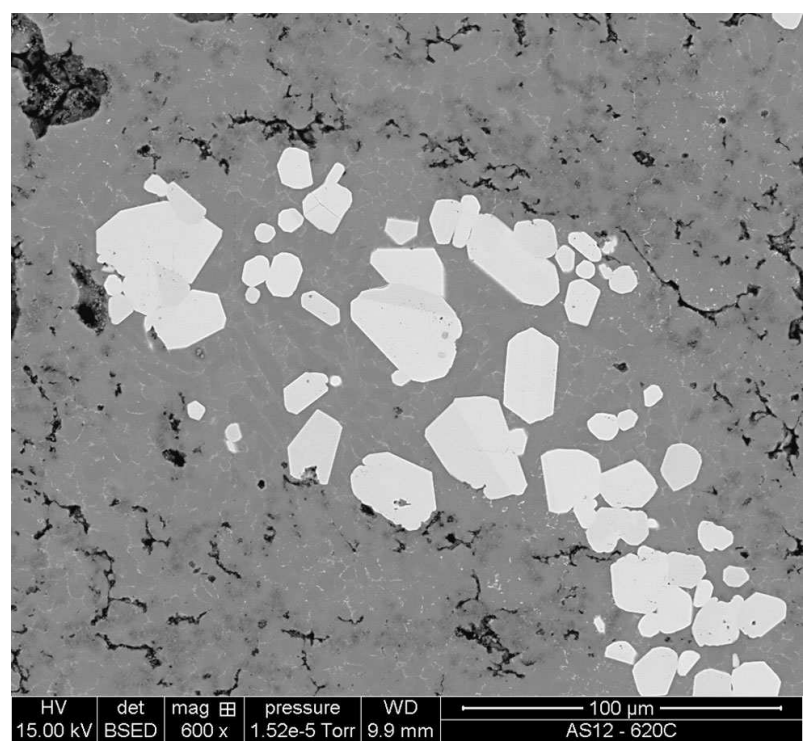

Fig. 1 Backscattered micrograph of an $\mathrm{Al}-12$ at.\%Si liquid saturated in Ti after $140 \mathrm{~h}$ at $620^{\circ} \mathrm{C}$ and water quenching, revealing the presence of crystals 


\section{Author's personal copy}

Table 1 Chemical composition of the solid compounds equilibrated with different Al-Si liquid compositions between Al-3 at.\%Si and Al-13 at.\%Si

\begin{tabular}{|c|c|c|c|c|c|c|c|}
\hline \multirow[b]{2}{*}{ Temperature } & \multicolumn{3}{|c|}{ Initial composition (at.\%) } & \multicolumn{3}{|c|}{$\begin{array}{l}\text { Compositions of the solid phase as } \\
\text { determined by EDS analysis (at.\%) }\end{array}$} & \multirow[b]{2}{*}{ Phase } \\
\hline & $\mathbf{A l}$ & $\mathbf{S i}$ & $\mathbf{T i}$ & Al & $\mathbf{S i}$ & $\mathbf{T i}$ & \\
\hline \multirow[t]{11}{*}{$620^{\circ} \mathrm{C}$} & Matrix & 5 & 0.4 & 64.06 & 10.85 & 25.09 & $\mathrm{Al}_{3} \mathrm{Ti}$ fcc_Al \\
\hline & $\ldots$ & 7 & 0.4 & 63.27 & 12.02 & 24.71 & $\mathrm{Al}_{3} \mathrm{Ti}$ \\
\hline & $\ldots$ & 9 & 0.4 & 60.9 & 13.1 & 26 & $\mathrm{Al}_{3} \mathrm{Ti}$ \\
\hline & $\ldots$ & 9.5 & 0.4 & 60.9 & 12.95 & 26.15 & $\mathrm{Al}_{3} \mathrm{Ti}$ \\
\hline & & & & 12.3 & 53.8 & 33.9 & $\tau_{2}$ \\
\hline & $\ldots$ & 10 & 0.4 & 11 & 55.3 & 33.7 & $\tau_{2}$ \\
\hline & $\ldots$ & 10.5 & 0.4 & 11 & 54.4 & 34.6 & $\tau_{2}$ \\
\hline & $\ldots$ & 11 & 0.4 & 11.5 & 54.9 & 33.6 & $\tau_{2}$ \\
\hline & $\ldots$ & 12 & 0.4 & 11.1 & 54.6 & 34.3 & $\tau_{2}$ \\
\hline & & & & 8.9 & 56.9 & 34.2 & $\tau_{1}$ \\
\hline & $\ldots$ & 13 & Saturated & 8.9 & 56.9 & 34.2 & $\tau_{1}$ \\
\hline \multirow[t]{7}{*}{$680^{\circ} \mathrm{C}$} & $\ldots$ & 3 & 0.4 & 65.5 & 9.3 & 25.2 & $\mathrm{Al}_{3} \mathrm{Ti}$ \\
\hline & $\ldots$ & 5 & 0.4 & 63.7 & 11.3 & 25 & $\mathrm{Al}_{3} \mathrm{Ti}$ \\
\hline & $\ldots$ & 9 & 0.4 & 61.6 & 12.3 & 26.1 & $\mathrm{Al}_{3} \mathrm{Ti}$ \\
\hline & $\ldots$ & 10 & 0.4 & 60.6 & 14.2 & 25.2 & $\mathrm{Al}_{3} \mathrm{Ti}$ \\
\hline & $\ldots$ & 11 & 0.4 & 11.8 & 53.5 & 34.7 & $\tau_{2}$ \\
\hline & $\ldots$ & 12 & 0.4 & 11.9 & 54.4 & 33.7 & $\tau_{2}$ \\
\hline & $\ldots$ & 13 & 0.4 & 10.3 & 55.9 & 33.8 & $\tau_{2}$ \\
\hline \multirow[t]{5}{*}{$727^{\circ} \mathrm{C}\left(\right.$ from $\left.^{[11]}\right)$} & $\ldots$ & 9 & 0.4 & 61.7 & 13.9 & 25.2 & $\mathrm{Al}_{3} \mathrm{Ti}$ \\
\hline & $\ldots$ & 10 & 0.4 & 61.4 & 13.5 & 25.1 & $\mathrm{Al}_{3} \mathrm{Ti}$ \\
\hline & $\ldots$ & 11 & 0.4 & 60.7 & 14.3 & 25 & $\mathrm{Al}_{3} \mathrm{Ti}$ \\
\hline & & & & 13.3 & 53.3 & 33.4 & $\tau_{2}$ \\
\hline & $\cdots$ & 12 & 0.4 & 12.9 & 53.7 & 33.4 & $\tau_{2}$ \\
\hline
\end{tabular}

Isothermal treatment is performed at 620,680 or $727^{\circ} \mathrm{C}$ during a minimum of $150 \mathrm{~h}$ and is followed by water quenching. Quantitative composition is obtained by EDS analysis with pure elements as standards and PAP corrections

pattern especially in the case of alloys with a low Ti content $(0.4$ at. $\%)$ in which the amount of crystals is small. One can notice that the structural and compositional similarities between these two compounds have already led some authors to misidentifications and ambiguous results. ${ }^{[14]}$ Concerning their composition range, some disagreements exist in the literature. According to Shob et al. ${ }^{[13]}$ and Liu et al. ${ }^{[12]}$ the homogeneity region of $\tau_{2}-\mathrm{Ti}\left(\mathrm{Si}_{x} \mathrm{Al}_{1-x}\right)_{2}$ is located along an a line of constant $\mathrm{Ti}$ concentration of 33 at.\% from 10 to 20 at.\%Al; whereas Raman and Schubert ${ }^{[18]}$ and Peronnet et al. ${ }^{[11]}$ have reported the existence of an homogeneity range for both elements. Different compositions have also been reported in the literature for $\tau_{1}-\mathrm{Ti}_{7} \mathrm{Al}_{5} \mathrm{Si}_{12}$. Raman and Schubert ${ }^{[18]}$ reported a noticeable homogeneity range of $8-15$ at.\%Al, 55-62 at.\%Si and 30-33 at.\%Ti; whereas Peronnet et al. ${ }^{[1]}$ obtained a smaller one $(9-10$ at.\%Al, $56-57$ at.\%Si and 33-34 at.\%Ti) and Liu et al. ${ }^{[12]}$ a nearly stoichiometric compound with a typical composition that is $\mathrm{Al}_{7.5} \mathrm{Si}_{58.8} \mathrm{Ti}_{33.7}$. Finally, discrimination between the two ternary compounds is quite difficult.

The results obtained at $620{ }^{\circ} \mathrm{C}$ allow to determine the compositions of liquid involved in a three phase equilibria with two solid phases: $\mathrm{Al}_{3} \mathrm{Ti}$ and $\tau_{2}-\mathrm{Ti}\left(\mathrm{Si}_{x} \mathrm{Al}_{1-x}\right)_{2}$ are in equilibrium with a liquid containing about 9.5 at. $\% \mathrm{Si}$, while $\tau_{2}-\mathrm{Ti}\left(\mathrm{Si}_{x} \mathrm{Al}_{1-x}\right)_{2}$ and $\tau_{1}-\mathrm{Ti}_{7} \mathrm{Al}_{5} \mathrm{Si}_{12}$ coexist with a liquid characterized by a $\mathrm{Si}$ amount of about 12 at.\%Si. Those liquid compositions have to be compared with the ones determined by Peronnet et al. ${ }^{[11]}$ for the same three phase equilibria at $727{ }^{\circ} \mathrm{C}$ that are respectively 11 and 16 at.\% Si. We take advantage of these three phase equilibria where the two intermetallic compounds $\tau_{2}-\operatorname{Ti}\left(\mathrm{Si}_{x} \mathrm{Al}_{1-x}\right)_{2}$ and $\tau_{1}-\mathrm{Ti}_{7} \mathrm{Al}_{5} \mathrm{Si}_{12}$ coexist to deduce criteria allowing the distinction of the two phases: the aluminium content of $\tau_{1}-\mathrm{Ti}_{7} \mathrm{Al}_{5} \mathrm{Si}_{12}$ is lower than 9 at.\% over the whole temperature range (from 620 to $727^{\circ} \mathrm{C}$ ), while it is higher than 10 at. $\%$ for $\tau_{2}-\mathrm{Ti}\left(\mathrm{Si}_{x} \mathrm{Al}_{1-x}\right)_{2}$ in the same range.

\subsection{Ti Solubility in Al-Si Melts}

The procedure of liquidus determination by liquid sampling and combined analysis by EPMA and chemical analysis has been firstly validated upon the Al-Ti binary. Original results have been already published. ${ }^{[23]}$ To illustrate the reliability of the values of solubility obtained by the present procedure, Fig. $2 \mathrm{of}^{[23]}$ is reproduced in Fig. 2 of the present paper where results are compared both with other 


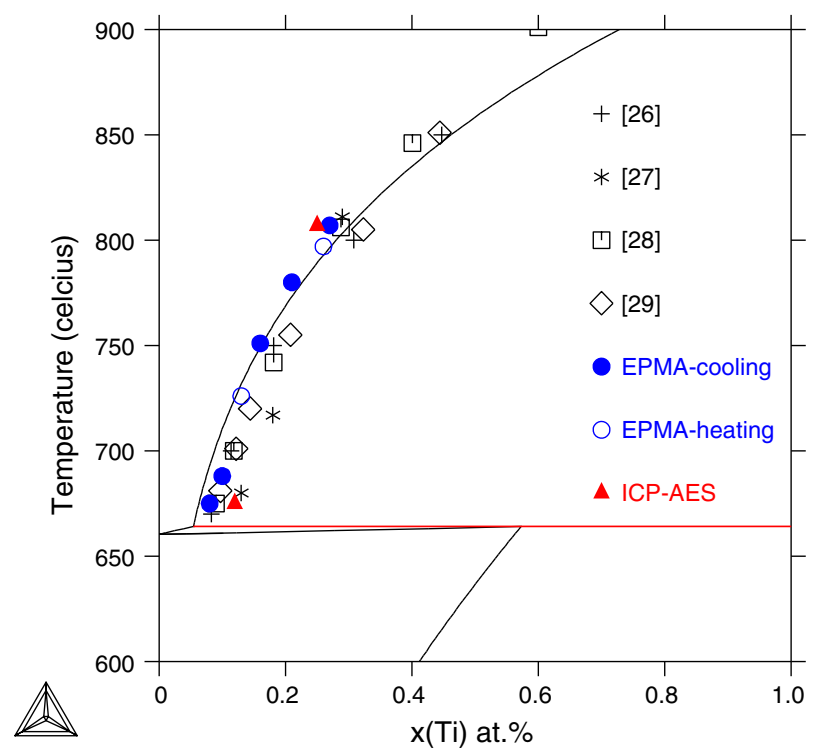

Fig. 2 Solubility limit of $\mathrm{Ti}$ in liquid $\mathrm{Al}$ determined by isothermal experiments at different temperatures and by using different analytical techniques: filled triangles are ICP-AES analysis, circles are EPMA analysis in WDS mode (the liquid sample is taken respectively during cooling - filled circles - and during heating - open circles). Experimental data are compared to previous experimental determinations ${ }^{[25-28]}$ and to the calculated liquidus from Ref 24. (Figure reproduced from Ref 23 by courtesy of Journal of Phase Equilibria and Diffusion)

experimental values and the accepted optimization of Kattner et al. ${ }^{[2]}$ It can firstly be noted that chemical analysis and WDS analysis lead to a coherent set of solubility limit values for Ti in pure Al liquid. Moreover, the similarity of $\mathrm{Ti}$ contents obtained after a cooling-i.e. during precipitation of $\mathrm{Al}_{3} \mathrm{Ti}$ - or a heating step-i.e. during dissolution of $\mathrm{Al}_{3} \mathrm{Ti}$ - is a clear indication that sampling of the liquid is performed when thermodynamic equilibrium is reached. Finally, the agreement with other experimental studies ${ }^{[25-28]}$ and the thermodynamic description of Kattner et al. ${ }^{[24]}$ is fairly good. It is noteworthy that the same agreement is observed with more recent optimizations. ${ }^{[29,30]}$ These results validate the use of this experimental procedure for the determination of liquidus composition in the case of binary Al-Si alloys.

Three different Al-Si alloys have been studied: one hypoeutectic alloy Al-9 at.\% $\%$, a nearly eutectic alloy Al13 at.\%Si and an hyper-eutectic one Al-18 at.\%Si. From the results presented in the previous section upon the nature of the solid phase in equilibrium with liquid, it has to be noted that for each alloy, the solid phase is characterized by a $\mathrm{Si}$ content greater than that of the nominal composition (about respectively 13 at. $\%$ for $\mathrm{Al}_{3} \mathrm{Ti}$ and 50 at.\% for the ternary compounds). As a consequence, partition of the silicon between the liquid and the solid phase leads to a Si content of the liquid that is lowered compared to the nominal one. By considering the mass conservation applied on $\mathrm{Si}$ and $\mathrm{Ti}$, the real Si content of the liquid can be calculated with the following equation ( $y$ represents the mass fractions):
$y_{\mathrm{Si}}^{\mathrm{L}}=y_{\mathrm{Si}}^{0}+\frac{y_{\mathrm{Ti}}^{0}-y_{\mathrm{Ti}}^{\mathrm{L}}}{y_{\mathrm{Ti}}^{\mathrm{S}}-y_{\mathrm{Ti}}^{0}}\left(y_{\mathrm{Si}}^{0}-y_{\mathrm{Si}}^{\mathrm{S}}\right)$,

where $y_{\mathrm{Si}}^{0}$ and $y_{\mathrm{Ti}}^{0}$ are the $\mathrm{Si}$ and $\mathrm{Ti}$ nominal compositions, $y_{\mathrm{Ti}}^{L}$ the Ti content of the liquid as determined by EPMA or ICP analysis, and $y_{\mathrm{Si}}^{\mathrm{S}}$ and $y_{\mathrm{Ti}}^{\mathrm{S}}$ the composition of the solid phase in $\mathrm{Si}$ and $\mathrm{Ti}$, respectively. It appears that the actual $\mathrm{Si}$ content of the liquid even more deviates from the nominal composition as the solid formed is Si-rich (the term in parenthesis) and as the initial Ti composition is beyond the solubility limit (numerator term). Therefore, the nominal compositions in $\mathrm{Ti}$ of the $\mathrm{Al}-\mathrm{Si}$ melt has been respectively fixed at 1.06, 0.93 and 0.99 at.\% for the Al-9 at.\%Si, Al13 at. $\% \mathrm{Si}$ and $\mathrm{Al}-18$ at.\%Si alloys. Moreover, it can be easily verified from the results in Ti composition of the liquid (see Fig. 3) that the deviation from the Si nominal composition is lower than 0.5 at.\%. Then, one can inferred that the actual $\mathrm{Si}$ content of the liquid is not significantly influenced by precipitation of the solid phase and therefore corresponds to the nominal one.

The results for the three alloys are respectively presented in Fig. 3a-c with filled symbol for EPMA results and open ones for chemical analysis. For sake of comparison, the liquidus curve calculated with the thermodynamic assessment of Gröbner et al. ${ }^{[17]}$ is also added on each figure. As concerns the Al-Ti binary system, the results obtained by the two analysis techniques (ICP-AES and WDS-EPMA) are in fairly good agreement. Moreover, it should be emphasized that EPMA results obtained on liquid sampling both during cooling, i.e. desaturation of the liquid by precipitation of Tirich solid phase, or heating - i.e. saturation of the liquid by dissolution of Ti-rich solid phase - are both aligned on the same liquidus curve. This convergence attests that the experimental values are obtained once thermodynamic equilibrium is reached. It appears from these figures that the Si content of the alloy has only a weak influence on the Ti solubility that remains between 0.05 and 0.5 at. $\%$ in the temperature range of the study $\left(600-800^{\circ} \mathrm{C}\right)$. Finally, experimental solubility values are larger than the ones calculated from the thermodynamic assessment of Gröbner et al. ${ }^{[17]}$ by a factor of about 10 for the three Si contents.

\subsection{Determination of the Last Ternary Invariant}

Liu et al. ${ }^{[12]}$ and Zakharov et al. ${ }^{[10]}$ are in disagreement about the nature of the last ternary invariant but both authors agree on two points: the phases involved (Al-fcc, Si and $\left.\tau_{1}-\mathrm{Ti}_{7} \mathrm{Al}_{5} \mathrm{Si}_{12}\right)$ and the composition of the liquid phase that is about 12.5 at.\% $\%$ i.

Figure 4 shows the morphology of the two solid phases Si and $\tau_{1}-\mathrm{Ti}_{7} \mathrm{Al}_{5} \mathrm{Si}_{12}$ in the same specimen, an Al-Si alloy with 20 at.\%Si saturated in $\mathrm{Ti}$, after the same heat treatment, for $140 \mathrm{~h}$ at $750{ }^{\circ} \mathrm{C}$, but (i) after water quenching (Fig. 4a) and (ii) after slow inertial cooling (Fig. 4b). After water quenching, the crystals of $\tau_{1}-\mathrm{Ti}_{7} \mathrm{Al}_{5} \mathrm{Si}_{12}$ in equilibrium with the liquid alloy typically appear under the form of platelets with large smooth faces 50-150 $\mu \mathrm{m}$ in length and 30-40 $\mu \mathrm{m}$ in thickness. After cooling at a slow rate, these crystals exhibit a very different morphology, as illustrated in Fig. 4b. 


\section{Author's personal copy}
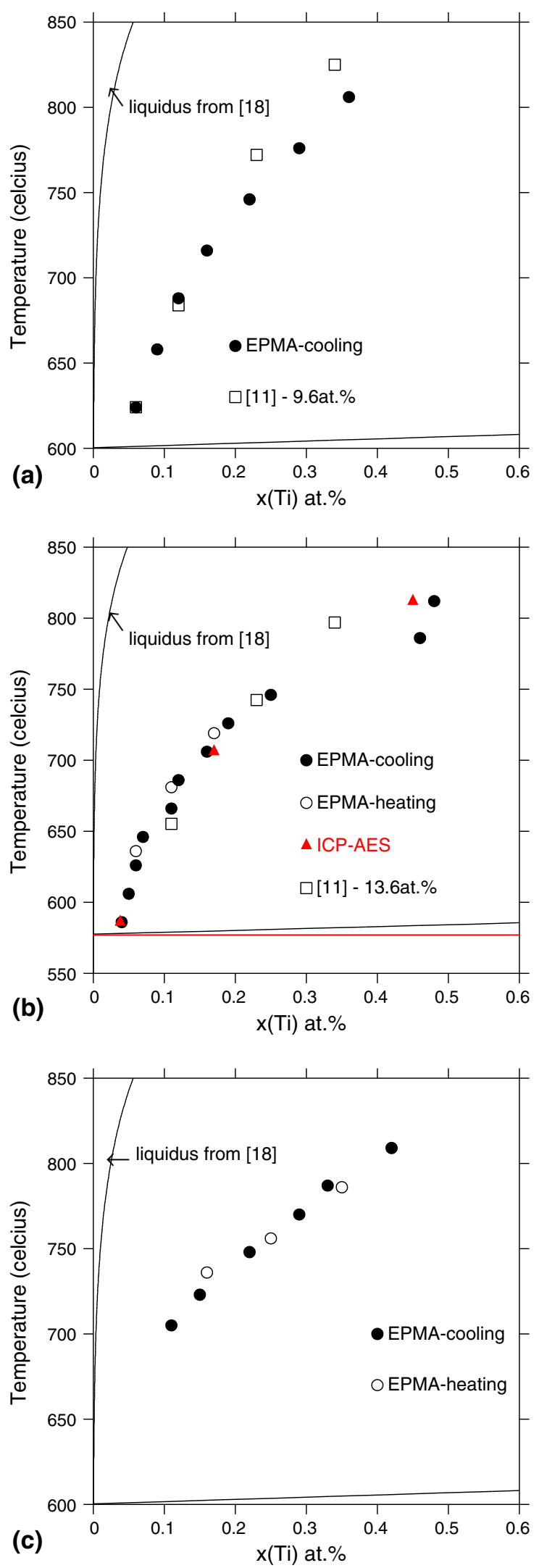

4 Fig. 3 Solubility limits of Ti in liquid Al-Si alloys determined by isothermal experiments at different temperatures and by using different analytical techniques: filled triangle are ICP analyses, circles are EPMA analyses in WDS mode (sampling of the liquid is respectively performed during cooling - filled circles - and during heating - open circle). (a) Al-9 at.\%Si alloy, (b) Al-13 at.\% $\% \mathrm{Si}$ alloy, (c) Al-18 at.\%Si alloy. Experimental data are compared to the calculated liquidus (solid line, ${ }^{[17]}$ ) and to experimental solubility values of Zakharov et al. (open square, ${ }^{[10]}$ ) for nearly equivalent $\mathrm{Si}$ content

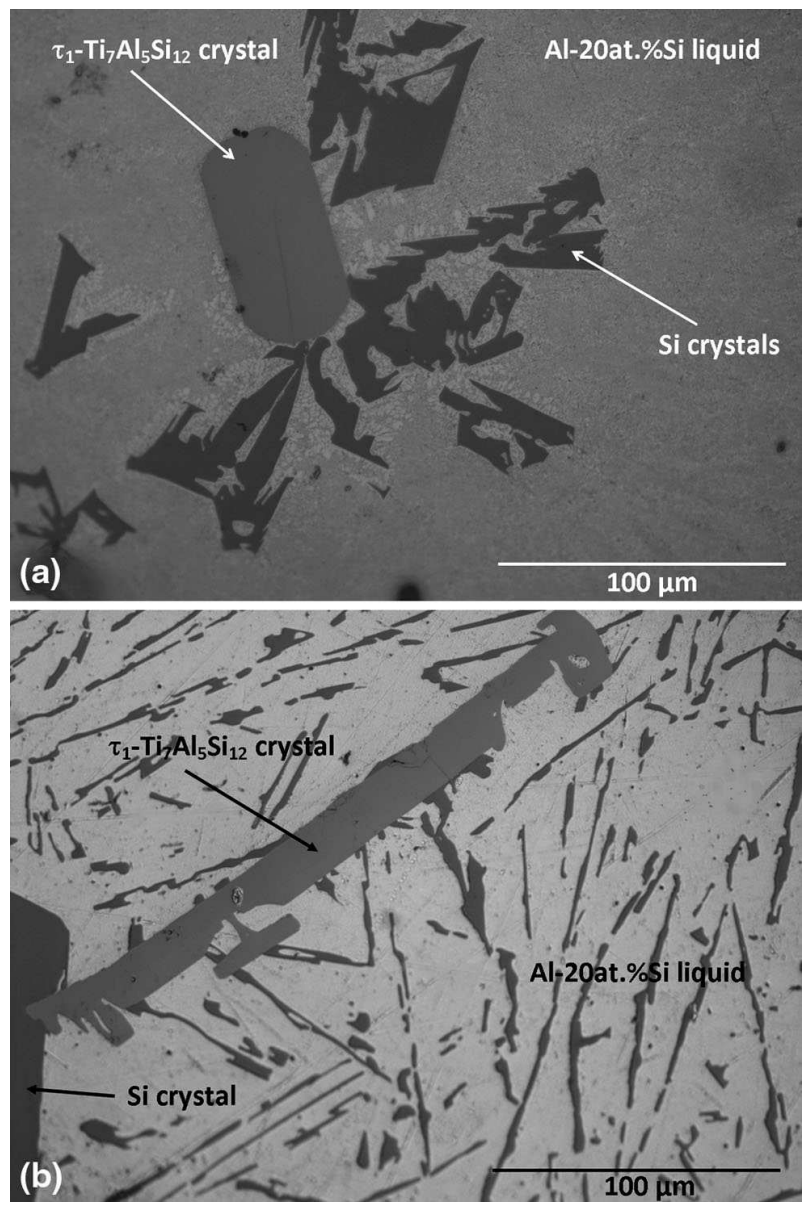

Fig. 4 Microstructure of an Al-20 at.\%Si liquid, Ti-saturated after $140 \mathrm{~h}$ of heat treatment and (a) water quenching, (b) slow inertial cooling

The smooth faces have disappeared and the interface between the $\tau_{1}-\mathrm{Ti}_{7} \mathrm{Al}_{5} \mathrm{Si}_{12}$ and the solidified $\mathrm{Al}-20$ at. $\% \mathrm{Si}$ liquid has become sharply uneven. This is the signature of a peritectic transition occurring during cooling.

The nature of the last invariant can also be determined by the relative position of the liquid and solid compositions: in the case of a ternary eutectic the liquid composition has to be included in the triangle formed by the three solid phases. ${ }^{[31]} \mathrm{As} \mathrm{Si}$ and $\tau_{1}-\mathrm{Ti}_{7} \mathrm{Al}_{5} \mathrm{Si}_{12}$ can be considered as stoichiometric compounds, the eutectic or peritectic nature 


\section{Author's personal copy}

of the last invariant mainly depends on the relative solubility of $\mathrm{Ti}$ in the $\mathrm{Al}-12.5$ at.\% $\mathrm{Si}$ liquid and in the $\mathrm{Al}$ solid solution. The solubility of $\mathrm{Ti}$ in Al-Si liquids has been determined to be as low as 0.04 at. $\%$ at $580{ }^{\circ} \mathrm{C}$, without any significant influence of the $\mathrm{Si}$ content. According to the optimization from Kattner et al. ${ }^{[24]}$ the solubility of Ti in $\mathrm{Al}$ solid solution, at the same temperature, is about 0.46 at.\%, i.e. one order of magnitude higher. If we consider that the $\mathrm{Ti}$ solubility in solid Al is not significantly influenced by the $\mathrm{Si}$ content (by analogy with the liquid Al-Si alloy), then the composition of the liquid cannot lie inside the triangle Al-Si- $\tau_{1}$.

The nature of the last invariant transformation can also be derived from the DSC investigations performed on the binary and ternary samples having the composition $\mathrm{Al}_{79.3} \mathrm{Si}_{20.7}$ and $\mathrm{Al}_{78.84} \mathrm{Si}_{20.53} \mathrm{Ti}_{0.62}$, respectively. By averaging the values of four measurements done on the binary Al-Si sample, the temperature of the eutectic plateau was found to be $577.3 \pm 0.9{ }^{\circ} \mathrm{C}$. This result is in very good agreement with the value reported by Zakharov et al. ${ }^{[10]}$ $\left(577.5^{\circ} \mathrm{C}\right)$. The temperature of the last invariant reaction in the Al-Si-Ti system has been determined by averaging nine values: $578.3 \pm 0.2{ }^{\circ} \mathrm{C}$. This result confirms the existence of a peritectic reaction rather than a ternary eutectic, which agrees well with ${ }^{[10]}$ where the existence of peritectic equilibrium at $579{ }^{\circ} \mathrm{C}$ is quoted.

Finally all the experimental results, morphology of crystals, composition of phases on the isothermal sections and DSC measurements, are self-consistent and support the conclusion that the last invariant is a quasi-peritectic $\left(\mathrm{L}+\tau_{1}-\mathrm{Ti}_{7} \mathrm{Al}_{5} \mathrm{Si}_{12} \Leftrightarrow \mathrm{Al}+\mathrm{Si}\right)$ rather than a ternary eutectic.

\subsection{Liquidus Projection}

Combining the nature of solid phases in equilibrium with the different Al-Si liquid and the values of Ti solubility, a tentative liquidus projection of the Al-rich corner has been obtained.

Two monovariant lines are extensions in the ternary of invariant reactions in the Al-Ti and Al-Si binary systems.

The first monovariant line $\left(\mathrm{pU}_{10}\right.$ in Fig. 5), $\mathrm{L}+\mathrm{Al}_{3} \mathrm{Ti} \Leftrightarrow \mathrm{Al}$, is coming from the $\mathrm{Al}-\mathrm{Ti}$ peritectic point at $665{ }^{\circ} \mathrm{C}$ and 0.08 at.\% Ti. ${ }^{[32]}$ From Table 1, it appears that at $620{ }^{\circ} \mathrm{C}$, a liquid containing 5 at.\% $\%$ and saturated in $\mathrm{Ti}$ is in equilibrium simultaneously with $\mathrm{Al}_{3} \mathrm{Ti}$ and with the Al-fcc solid solution. At $620{ }^{\circ} \mathrm{C}$, the solubility value measured for an Al-9 at.\% $\%$ alloy, in equilibrium with $\mathrm{Al}_{3} \mathrm{Ti}$ is 0.06 at.\%Ti (see Fig. 3a). Moreover, at this temperature, the amount of $\mathrm{Ti}$ in a saturated liquid appears not to vary significantly with the $\mathrm{Si}$ content of the liquid (see Fig. 2, 3a and b). Consequently, a Ti solubility of 0.06 at. $\%$ has been considered for Ti solubility in Al-5 at. $\% \mathrm{Si}$ at $620^{\circ} \mathrm{C}$ in Fig. 5.

In the Al-Si binary system, an eutectic reaction $\mathrm{L} \Leftrightarrow \mathrm{Al}+\mathrm{Si}$ is observed at $577^{\circ} \mathrm{C}$ with a liquid composition that is of 12.5 at.\% $\%$ after Ref 10 . According to Ref 10,12 , the monovariant line relying the Al-Si binary eutectic point with the nearest invariant reaction in the Al-Si-Ti ternary system is characterized by a nearly iso-concentration

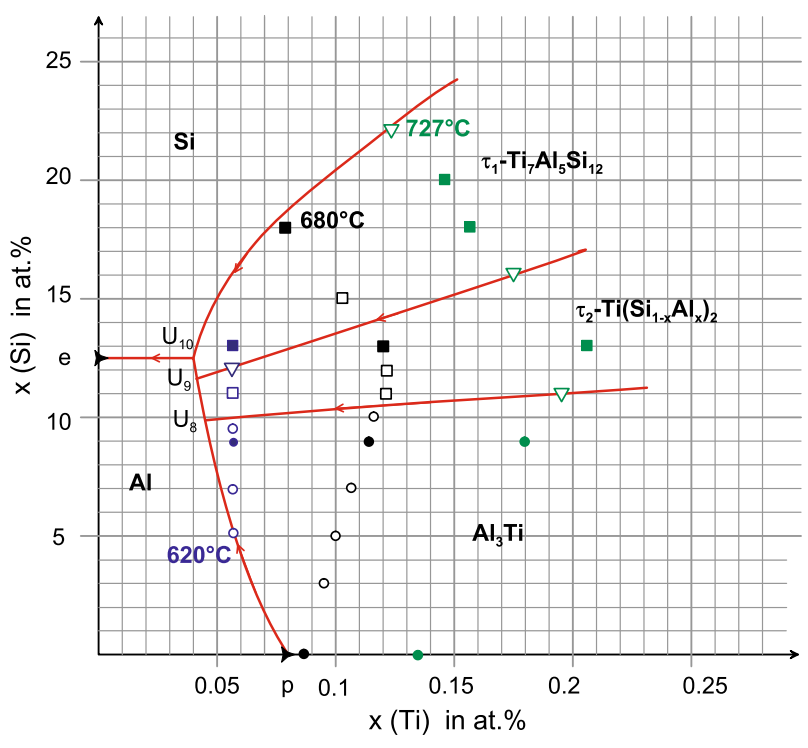

Fig. 5 Liquidus projection close to the Al-rich corner of the Al-Si-Ti system. Filled and empty symbols respectively correspond to isoplethic points ( $\mathrm{Ti}$ content is measured) and to isothermal points ( $\mathrm{Ti}$ content is interpolated or extrapolated). The meaning of symbols is respectively equilibrium with $\mathrm{Al}_{3} \mathrm{Ti}$ for circles, equilibrium with $\tau_{2}-\mathrm{Ti}\left(\mathrm{Si}_{1-x} \mathrm{Al}_{x}\right)_{2}$ or $\tau_{1}-\mathrm{Ti}_{7} \mathrm{Al}_{5} \mathrm{Si}_{12}$ for squares and three phase equilibria for triangles

of $\mathrm{Si}$ (line $\mathrm{eU}_{10}$ on Fig. 5). This is consistent with the results of the present study and has been considered in Fig. 5 .

Even if they disagree on the nature of the last invariant reaction, Liu et al. ${ }^{[12]}$ and Zakharov et al. ${ }^{[10]}$ agree on the fact that this last reaction occurs at the intersection of the two preceding monovariant lines and a third one corresponding to the three-phased equilibrium between the liquid, solid $\mathrm{Si}$ and $\tau_{1}-\mathrm{Ti}_{7} \mathrm{Al}_{5} \mathrm{Si}_{12}: \mathrm{L} \Leftrightarrow \tau_{1}+\mathrm{Si}$. According to Peronnet et al., ${ }^{11]}$ at $727^{\circ} \mathrm{C}$, a liquid containing 22 at.\% $\% \mathrm{Si}$ is in equilibrium both with $\mathrm{Si}$ and $\tau_{1}-\mathrm{Ti}_{7} \mathrm{Al}_{5} \mathrm{Si}_{12}$ and thus belongs to this monovariant line. The solubility of $\mathrm{Ti}$ in Al-Si alloys has been measured to decrease with temperature and in the case of the $\mathrm{Al}-13$ at.\% $\%$ alloy (a liquid close to the one of the liquid involved in the last invariant reaction) the lowest value of 0.04 at.\% was obtained at $580{ }^{\circ} \mathrm{C}$. Moreover, after $210 \mathrm{~h}$ of heat treatment at $620^{\circ} \mathrm{C}$ and water quenching, the solid phase in equilibrium with the same Al-13 at.\%Si alloy has been identified as $\tau_{1}-\mathrm{Ti}_{7} \mathrm{Al}_{5} \mathrm{Si}_{12}$ (see Table 1). This alloy composition is therefore located on the $\tau_{1}-\mathrm{Ti}_{7} \mathrm{Al}_{5} \mathrm{Si}_{12}$ liquidus surface, nearby the monovariant line. As a consequence, it can be considered that the composition of the liquid involved in the last quasi-peritectic reaction is close to 12.5 at.\% $\mathrm{Si}$ and 0.04 at.\%Ti. These values are consistent with the composition of the liquid at intersection between the lines $\mathrm{pU}_{10}$ and $\mathrm{eU}_{10}$ (see Fig. 5).

From Table $1, \mathrm{Al}_{3} \mathrm{Ti}$ is in equilibrium with $\mathrm{Al}-\mathrm{Si}$ melts containing up to 11 at. $\% \mathrm{Si}$ at $727{ }^{\circ} \mathrm{C}$, about 10.5 at. $\% \mathrm{Si}$ at $680{ }^{\circ} \mathrm{C}$ and about 9.5 at.\% $\%$ it $620{ }^{\circ} \mathrm{C}$. These results give information about the position of the monovariant line 
corresponding to the upper limit of the $\mathrm{Al}_{3} \mathrm{Ti}$ primary crystallization surface ending at $\mathrm{U}_{8}$.

Peronnet et al. reported that a liquid with a $\mathrm{Si}$ content of 16 at. $\% \mathrm{Si}$ is simultaneously in equilibrium with $\tau_{2}-\mathrm{Ti}\left(\mathrm{Si}_{1-x} \mathrm{Al}_{x}\right)_{2}$ and $\tau_{1}-\mathrm{Ti}_{7} \mathrm{Al}_{5} \mathrm{Si}_{12}$. This point should therefore belong to the monovariant line labeled $\mathrm{P}_{2} \mathrm{U}_{9}$ by Liu et al. ${ }^{[12]}$ In the present study, the same three phase equilibrium has been found at $620{ }^{\circ} \mathrm{C}$ with a liquid composition that is about 12 at.\%Si. Those two points give the local orientation of the monovariant line that is in agreement with the preceding ones (see Fig. 5).

\section{Conclusions}

The nature of liquid/solid phase equilibria and the solubility of $\mathrm{Ti}$ in different $\mathrm{Al}-\mathrm{Si}$ liquids have been determined experimentally in the Al-rich corner of the Al-Si-Ti system below $800{ }^{\circ} \mathrm{C}$. From isothermal (diffusion) experiments it can be concluded that, in contradiction with the assessment of Gröbner et al., ${ }^{[17]} \mathrm{Al}_{3} \mathrm{Ti}$ (with a significant substitution of $\mathrm{Al}$ by $\mathrm{Si}$ ) is in equilibrium with $\mathrm{Al}-\mathrm{Si}$ melts the silicon content of which extends over a wide range: from 0 to 11 at. $\% \mathrm{Si}$ at $727^{\circ} \mathrm{C}$, this $\mathrm{Si}$ content still ranges from 0 to 9.5 at. $\%$ Si at $620{ }^{\circ} \mathrm{C}$.

The solubility of Ti in Al-Si melts is slightly increased in comparison with pure liquid Al. The values are lower than 0.5 at. $\%$ and are not significantly influenced by the $\mathrm{Si}$ content of the liquid. Upon cooling, the last invariant reaction corresponding to the complete crystallization of the liquid is found to be quasi-peritectic. This reaction that has to be written $\left(\mathrm{L}+\tau_{1}-\mathrm{Ti}_{7} \mathrm{Al}_{5} \mathrm{Si}_{12} \Leftrightarrow \mathrm{Al}+\mathrm{Si}\right)$ occurs at a temperature of $578.3 \pm 0.2{ }^{\circ} \mathrm{C}$ for a $\mathrm{Si}$ content in the liquid of 12.5 at.\% $\%$ i. At $620{ }^{\circ} \mathrm{C}$ a liquid with 9.5 at. $\% \mathrm{Si}$ is still in equilibrium with $\mathrm{Al}_{3} \mathrm{Ti}$ and $\tau_{2}-\mathrm{Ti}\left(\mathrm{Si}_{x} \mathrm{Al}_{1-x}\right)_{2}$, therefore, two invariant reactions should intervene in the limited range of temperature from 620 to $578{ }^{\circ} \mathrm{C}$. A tentative liquidus projection based on the both isothermal and isoplethic sections is proposed.

\section{Acknowledgments}

Chemical microanalyses have been performed by the inorganic analysis team of Dr. Ayouni of the Analytical Sciences Institute. SEM and EPMA characterizations were performed at the "Centre Technologique des Microstructures, Universite Lyon 1". The authors acknowledge gratefully the members of these services for their assistance.

\section{References}

1. M. Easton and D. Stjohn, Grain Refinement of Aluminum Alloys: Part I. The Nucleant and Solute Paradigms-A Review of the Literature, Metall. Mater. Trans. A, 1999, 30(6), p 1613-1623

2. M. Easton and D. StJohn, Grain Refinement of Aluminum Alloys: Part II. Confirmation of, and a Mechanism for, the Solute Paradigm, Metall. Mater. Trans. A, 1999, 30(6), p 1625-1633
3. L. Arnberg, L. Bäckerud, and H. Klang, Intermetallic Particles in Al-Ti-B-Type Master Alloys for Grain Refinement of Aluminium, Met. Technol., 1972, 9(1), p 7-13

4. B.S. Murty, S.A. Kori, and M. Chakraborty, Grain Refinement of Aluminium and Its Alloys by Heterogeneous Nucleation and Alloying, Int. Mater. Rev., 2002, 47(1), p 3-29

5. M. Abdel-Reihim, N. Hess, W. Reif, and M.E.J. Birch, Effect of Solute Content on the Grain Refinement of Binary Alloys, J. Mater. Sci., 1987, 22(1), p 213-218

6. M. Johnsson, Influence of $\mathrm{Si}$ and $\mathrm{Fe}$ on the Grain-Refinement of Aluminum, Z. Metall., 1994, 85(11), p 781-785

7. J.A. Spittle, J.M. Keeble, and M.A. Meshhedani, The Grain Refinement of Al-Si Foundry Alloys, Light Metals, R. Huglen, Ed., TMS, Warrendale, PA, 1997, p 795-800

8. T.E. Quested, A.T. Dinsdale, and A.L. Greer, Thermodynamic Evidence for a Poisoning Mechanism in the Al-Si-Ti System, Mater. Sci. Technol., 2006, 22(6), p 1126-1134

9. P. Perrot, The Al-Si-Ti System, Ternary Alloys, G. Petzow and G. Effenberg, Ed., VCH, Weinheim, 1988, p 557

10. A. Zakharov, I. Guldin, A. Arnold, and Y. Matsenko, PhaseEquilibria in the Al-Si-Ti System in the 10-14 Percent Si and 0-6 Percent Ti Concentration Range, Russ. Metall., 1998, 4, p $185-189$

11. M. Peronnet, F. Barbeau, F. Bosselet, J.C. Viala, and J. Bouix, Comportement Chimique du Titane Dans un Alliage Liquide Aluminium-Silicium, J. Phys. IV, 1999, 9(PR4), p 6

12. S. Liu, F. Weitzer, J.C. Schuster, N. Krendelsberger, and Y. Du, On the Reaction Scheme and Liquidus Surface in the Ternary System Al-Si-Ti, Int. J. Mater. Res., 2008, 99(7), p 705-711

13. O. Shob, H. Nowotny, and F. Benezovsky, The Ternary System (Titanium, Zirconium, Hafnium) Aluminum-Silicon, Planseeber. Pulvermetall., 1962, 10, p 65-71

14. S. Gupta, Intermetallic Compounds in Diffusion Couples of Ti with an Al-Si Eutectic Alloy, Mater. Charact., 2002, 49(4), p 321-330

15. M. Bulanova, L. Tretyachenko, M. Golovkova, and K. Meleshevich, Phase Equilibria in the $\alpha$-Ti-Al-Si Region of the Ti-Si-Al System, J. Phase Equilib. Diffus., 2004, 25(3), p 209-229

16. W.V. Youdelis, Calculated Al-Ti-Si Phase Diagram and Interpretation of Grain Refinement Results, Met. Sci., 1978, 12(8), p 363-366

17. J. Gröbner, D. Mirković, and R. Schmid-Fetzer, Thermodynamic Aspects of Grain Refinement of Al-Si Alloys Using Ti and B, Mater. Sci. Eng. A, 2005, 395(1-2), p 10-21

18. A. Raman and K. Schubert, The Constitution of Some Alloy Series Related to TiAl3. II. Investigations in Some T-Al-Si and T4...6-In Systems, Z. Metall., 1965, 56(1), p 44-52

19. T. Magnusson and L. Arnberg, Density and Solidification Shrinkage of Hypoeutectic Aluminum-Silicon Alloys, Metall. Mater. Trans. A, 2001, 32(10), p 2605-2613

20. J. Pouchou and F. Pichoir, Very High Elements x-RayMicroanalysis-Recent Models of Quantification, J. Microsc. Spectrosc. Electron., 1986, 11(4), p 229-250

21. C.J. Smithells, W.F. Gale, and T.C. Totemeier, Smithells Metals Reference Book, Volume 1, 4th ed., Butterworths, London, 1967

22. C. Brukl, H. Nowotny, O. Schob, and F. Benesovsky, Die Kristallstruckturen von TiSi, Ti(Al, Si)2 und $\mathrm{Mo}(\mathrm{Al}, \mathrm{Si}) 2$, Monatsh. Chem., 1961, 92(3), p 781-788

23. O. Dezellus, B. Gardiola, and J. Andrieux, On the solubility of Group IV elements (Ti, Zr, Hf) in liquid aluminium below $800{ }^{\circ} \mathrm{C}$, J. Phase Equilib. Diff., 2014. doi:10.1007/s11669013-0278-2

24. U.R. Kattner, J.-C. Lin, and Y.A. Chang, Thermodynamic Assessment and Calculation of the Ti-Al System, Metall. Trans. A, 1992, 23(8), p 2081-2090 


\section{Author's personal copy}

25. K. Shibata, T. Sato, and G. Ohira, The Solute Distributions in Dilute Al-Ti Alloys During Unidirectional Solidification, J. Cryst. Growth, 1978, 44(4), p 435-445

26. A. Abdel-Hamid, C.H. Allibert, and F. Durand, Equilibrium Between Titanium-Aluminum $\left(\mathrm{TiAl}_{3}\right)$ and Molten Aluminum: Results from the Technique of Electromagnetic Phase Separation, Z. Metall., 1984, 75(6), p 455-458

27. W.L. Fink, H. Van, and P.M. Budge, Constitution of highpurity aluminum-titanium alloys, Am. Inst. Min. Met. Eng., 1931, 393, p 18

28. M. Heckler, Solubility of Titanium in Liquid Aluminum, Aluminium (Dusseldorf), 1974, 50(6), p 405-407
29. V.T. Witusiewicz, A.A. Bondar, U. Hecht, S. Rex, and T.Y. Velikanova, The Al-B-Nb-Ti System: III. Thermodynamic Re-evaluation of the Constituent Binary System Al-Ti, J. Alloys Compd., 2008, 465(1-2), p 64-77

30. I. Ohnuma, Y. Fujita, H. Mitsui, K. Ishikawa, R. Kainuma, and K. Ishida, Phase Equilibria in the Ti-Al Binary System, Acta Mater., 2000, 48(12), p 3113-3123

31. A. Prince, Alloy Phase Equilibria, Elsevier Science, Amsterdam, 1966

32. J.C. Schuster and M. Palm, Reassessment of the Binary Aluminum-Titanium Phase Diagram, J. Phase Equilib. Diffus., 2006, 27(3), p 255-277 